\title{
Plant Growth Promoting Bacteria and their Prospective Role for Crop Improvement
}

\author{
Birhanu Babiye \\ *Corresponding Author: Birhanu Babiye, EIAR @ NABRC Holetta Profession :- Plant Biotechnology \\ Researcher Holetta, Ethiopia
}

\begin{abstract}
The sustainability of life on the earth is dependent on the soil characteristics because of soil has crucial role in agriculture so the dynamic nature of soil is a directly affected by soil microbes, In the current scenario increasing population in the world needs high agricultural yield so to fulfill the demand leading to production and utilization of chemical fertilizers and pesticides in the agricultural field but that caused the degradation of soil quality and remove soil fertility so current agricultural researcher are turn their attention to a safer and productive means of agricultural practice such as the use of plant growth promoter rhizobacteria for improving agricultural productivity to address population demand with environmental ecofriendly, plant growth promoter are improve agricultural productivity by direct and indirect mechanism for sustainable agriculture, in this review paper tray to review the mechanism that plant growth promoter rhizobacteria are use to enhance plant growth specifically bacterial trait that are use for increasing crop productivity, worlds current progress in utilization of plant growth promoter rhizobacteria for various application and the integration of biotechnology tool like metagenomics research and nanotechnology current and feature prospect for identification and utilization of such beneficial soil bacteria for agricultural sustainability are fully reviewed so this paper are used as information giver about new technology in agriculture .
\end{abstract}

Keywords: Rhizosphere, rhizobacteria, Rhizoplane and metagenomics.

\section{INTRODUCTION}

According to 2017 report currently around 7.6 billion people in the world and this rapid growth is expected to reach 8 billion around the year 2020 and in the coming ten to twenty year will be significance challenge to feed all the worlds people, based on this data to feed this the available and expected population the world needs to begin to greatly increase agricultural productivity with a sustainable and environmentally friendly manner by re-examine current and existing approaches(Bernard, 2012; Lucy et al., 2004)

Agriculture is one of the human activities that contributes increasing amount of chemical pollutants via excessive use of synthetic chemical to increase crop productivity to fulfill world population food demand such as chemical fertilizers, herbicides, fungicides, and insecticides but those chemicals has led to substantial decrease soil fertility by reducing $\mathrm{p}^{\mathrm{H}}$ and exchangeable bases and making nutrient unavailable to crops leading to loss of productivity therefore to remove or reduce this problem one possibility is to use soil microorganisms (bacteria, fungi, algae, etc.) that increase the nutrient uptake capacity and water use efficiency of plants and from those potential soil microorganisms bacteria such as plant growth promoting rhizobacteria (PGPR) are the most promising one because PGPR used to enhance plant health and promote plant growth rate without environmental contamination or with environmental eco-friendly (Pravin et al., 2016; Galloway et al., 2008; Gupta et al., 2015 )

Rhizobacteria are one of crucial component from soil component which are involved in various biotic activity of soil ecosystem and make the soil dynamic for nutrient and sustainable for crop improvement by means of enhance crop production by stimulate plant growth through mobilizing nutrients in soils, producing numerous plant growth regulators, protecting plants from phytopathogens by controlling or inhibiting them, improving soil structure and bioremediating the polluted soils by sequestering toxic heavy metal species and degrading xenobiotic compounds like pesticides (Ahemad. 2012; Hayat et al., 2010; Rajkumar et al., 2010; Chandler et al.,2008; Munees Ahemad et al .; 2014).

Rhizobacteria are the most and dominant deriving forces that means they are involved in recycling the soil nutrients consequently and play a crucial role for increasing soil fertility by means of providing 
Phytohormone production and siderophore production ,1-aminocyclopropane- 1-carboxylate, hydrogen cyanate $(\mathrm{HCN})$, ammonia production, nitrogenase activity and phosphate solubilization. In addition to with the normal plant growth promoting properties (Glick. 2012).

As current research and innovation indicate that in the worldwide currently there is an ongoing interesting research activity with greater impetus to explore a wide range of rhizobacteria possessing novel traits their very interesting role like heavy metal detoxifying potentials, pesticide degradation/ tolerance, salinity tolerance, biological control of phytopathogens and insects (Munees and Mulugeta, 2014)

The mechanisms of how rhizobacteria are mediate plant growth promotion are not completely identified because of most of $99 \%$ of rhizosphere bacteria are uncultivable so that they need other tools to understand their function and in cause of Ethiopia there is little scientific justification about PGPR however biotechnology tool have the great role to identify such rhizobacteria and their function how rhizobacteria are contribute their trait for crop improvement are understand so plant growth promoting rhizobacteria, have been reported to exhibit the above crucial function to promote plant growth and development (Khan et al., 2009; Zaidi et al., 2009).

The present review is have an objective attempt to shed scientific light about the concept of rhizobacteria in the current scenario, on the modes of action of PGPR, the role of PGPR as biofertilizer, and the advantages of biotechnology tool known as metagenomics towards identification of PGPR as well as the information generated from this review could be very beneficial to those who are concerned about the use of PGPR for agricultural sustainability and to apply biotechnology tool for identification of rhizobacteria with their functional genome analysis for crop improvement are discussed briefly.

\section{RHIZOSPHERE}

Rhizosphere also is the microbe storehouse and defined as the narrow zone of soil directly surrounding the root system where the biological and chemical features of the soil are influenced by the roots (Sushanto et al., 2018; Munees and Mulugeta, 2014; Walker et al., 200; Kundan et al., 2015).

The root system in the rhizosphere serve for anchorage and uptake of water and nutrients from the soil as well as use as chemical factory because phenolic compounds are synthesized and released to numerous underground interactions. The compounds released by plant roots act as chemical attractants for a huge number of heterogeneous microbial communities. The composition of these compounds depends upon the physiological status and species of plants and microorganisms (Kang et al., 2010).

Rhizosphere has three different components function in soil fertility and plant growth support, these are. Rhizosphere (soil):- the soil zone that regulates by roots through release of substrates for attraction of microbial activity. Rhizoplane:-the root surface that strongly binds with soil particles. Root:-the root that is colonized by microorganisms specially bacteria (Barea et al., 2005).

\subsection{Plant Growth Promoting Rhizobacteria (PGPR)}

Rhizobacteria is a group of symbiotic or non-symbiotic rhizosphere bacteria that can competent to colonize the root environment either their mode of action is directly beneficial to the plant or not. In the other way rhizobacteria are called Plant growth promoting rhizobacteria (PGPR) (Kloepper et al., 1991; Ahmad et al., 2008; Pravin et al., 2016; Kundan et al., 2015).Hence, the term "plant growth promoting bacteria" refers to bacteria that have the potential and the function to enhance plant growth by promoting various growth promoting trait (Ahmad et al., 2008).

\subsection{Forms of Plant Growth Promoting Rhizobacteria (PGPR)}

Based on the interactions with plants (PGPR) are grouped in to Extracellular or intercellular plant growth promoting rhizobacteria Extracellular or intercellular plant growth promoting rhizobacteria live outside the plant cell and inhabit the rhizosphere or the spaces between the cells of the root cortex, Example of such bacteria are Azotobacter, Serratia, Azospirillum, Bacillus, Caulobacter, Chromobacterium, Agrobacterium, Erwinia, Flavobacterium, Arthrobacter, Micrococcous, Pseudomonas, and Burkholderia. Intracellular plant growth promoting rhizobacteria (iPGPR) are symbiotic or endophytic bacteria that inhabit inside the specialized nodular structures of root cells, Allorhizobium, Bradyrhizobium, Mesorhizobium, Rhizobium and Frankia are some examples of such group (Bhattacharyya and Jha, 2012; Viveros et al., 2010; Gray et al ., 2005). 


\subsection{Mechanism of PGPR to Promote Plant Growth}

Plant growth promoting bacteria enhance plant growth using either direct mechanism or indirect mechanism; traits specific bacteria involve enhancing plant physiology and resistance to different phytopathogens through various modes of actions. However, the mode of action by different PGPR bacteria varies depending on the type of host plant but can be influenced by a number of biotic factors such as plant genotypes, plant developmental stages, plant defense mechanisms and other members of the microbial community and abiotic factors such as soil composition, soil management and climatic conditions (Vacheron et al., 2013; Gupta et al., 2015; Zakry et al., 2012; Garcia et al., 2015).

\subsubsection{Direct Mechanism}

In the case of using direct mechanism PGPR directly facilitates the growth and development of plants through direct contact to the plant for providing nutrient uptake or increases nutrient availability through nitrogen fixation, mineralization of organic compounds, solubilization of mineral nutrients. The production of Phytohormone and its effect on plan vary on the microbial strain and the plant species (Bhardwaj et al., 2014).

\section{Facilitating Resource Acquisition}

These are one way that bacteria promote plant growth by using their direct mechanism and the beststudied mechanisms of bacteria that are use for providing plants with resources/nutrients that they lack such as fixed nitrogen, iron, and phosphorus because of most of agricultural soils lack a sufficient amount of one or more of these compounds, Farmers have become increasingly dependent on chemical sources of nitrogen and phosphorus but Besides the cost of those chemical poses human and environmental hazards so the best option know a day are used a bacteria that have the potential to substitute nitrogen and phosphorus that is currently used (Bernard, 2012)

\section{Modulating Phytohormone Levels}

For the survival of a plant in both biotic and abiotic stress factor plants responsed to their environment and for plant growth and development Plant hormones play key roles, plant is able to adjust its metabolism and adjust the levels of their endogenous Phytohormone in order to decrease the negative effects of environmental condition to overcome the effects of growth limiting factor, so rhizobacteria have also produce or modulate Phytohormone under in vitro conditions and many PGPB can alter Phytohormone levels and affect plant hormonal balance and its response to stress (Davies, 2004; Glick et al., 2007 ; Salamone et al ., 2005)

\subsubsection{Indirect Mechanisms}

It is a mechanism in which the soil bacteria involve in prevention or neutralizing effects of phytopathogens on plants by producing repressive substances that increase natural resistance of the host. It helps plants grow actively under environmental stress or protect plants from infections. The contribution of PGPR in indirect mechanism are include production of hydrolytic enzymes (chitinases, cellulases, proteases, etc.), various antibiotics in response to plant pathogen, induction of systematic resistance against various pathogen and pests, and production of siderophore (Nivya, 2015; Gupta et al., 2014; Singh and Jha, 2015; Akhgar et al, 2014).

\subsection{Application PGPR Trait in Crop Improvement}

Most of the Soil is replete with a number of microscopic life such as bacteria, fungi, actinomycetes, protozoa, and algae, Bacteria are the most common (95\%) and the soil hosts a large number of bacteria around 108 to 109 cells per gram of soil but only about $1 \%$ bacterial cells in soil are generally culturable, Biotechnological tools have such a great role to identify such uncultivable bacteria present in the soil and the number and type of bacteria that are found in different soils are affected by the soil conditions such as temperature, moisture, salt, chemicals, number and types of plants found in those respective soils (Schoenborn et al., 2004; Glick et al., 1999).

Bacteria affects crops in three ways based on the interaction between soil bacteria and plants beneficial (bacteria that have a positive effect on plant), harmful (bacteria that have a negative effect on plant ) or neutral(bacteria that have nether positive or negative effect on plant ) hear below the impact of both direct and indirect mechanism to improve crop productivity is discussed (Lynch., 1990 ; Glick., 2012). 


\subsubsection{Nutrient Fixation}

Nutrient fixation is among the effect of plant growth promoting soil bacteria that increase the accessibility and concentration of nutrient by fixing their supply for plant growth and productivity, the most fixing nutrient by PGPB are nitrogen and use by plant in the form of nitrate (NO3-), ammonium $(\mathrm{NH} 4+)$, solubilize phosphate, a siderophore production, IAA production for different plant species (Goswami et al., 2014; Paredes and Lebeis., 2016; Xu et al., 2012; Kumar, 2016)

\subsubsection{Nitrogen Fixation}

Nitrogen is the most vital nutrient for plant growth and productivity Although $78 \%$ of nitrogen presents in the atmosphere due to that nitrogen remains unavailable to the plants (Govind et al., 2015; Gaby and Buckley, 2012 )

Biological nitrogen fixation is a direct mechanism effect of PGPR process that accounts approximately two-thirds of global nitrogen fixation and fixation process that are carried out either by symbiotic or non-symbiotic interaction with plants. Symbiotic PGPR bacteria can enter plant root and form nodule which have the potential to fix atmospheric N2Those are rhizobacterial strain Rhizobium sp, Azoarcus sp, Beijerinckia sp, Pantoea agglomerans, and K. pneumonia. Improves soil quality and enhances nodule formation of plant. N2 fixation process are regulated and carried out by specific gene called nif (involves in activating the iron protein, donating electrons, biosynthesizing the iron molybdenum cofactor and other regulatory genes mandatory for the synthesis and activity of the enzyme) in addition PGPR have the function on crops in new growth promoting activity, disease management and maintenance of the nitrogen level in soil (Damam et al., 2016; Shridhar, 2012; Ahemad and Kibret, 2014; Reed et al., 2011).

\subsubsection{Phosphate Solubilization}

Phosphorus is the second most essential nutrient next to nitrogen required by plants with adequate amount for optimum plant growth and plays an important function in all major metabolic processes such as energy transfer, signal transduction, respiration, macromolecular biosynthesis, and photosynthesis, Approximately 95-99\% of phosphorus present in the form of insoluble, immobilized, or precipitated, difficult for plants to absorb. Plants absorb phosphate only as monobasic (H2PO4-) and dibasic (HPO4-2) ions so soil bacteria are used for Solubilization and mineralization of phosphorus using important trait of phosphate-solubilizing bacteria that can be done by potential Phosphate solubilizing PGPR are in the genera Arthrobacter, Bacillus, Beijerinckia, Burkholderia, Enterobacter, Microbacterium Pseudomonas, Erwinia, Rhizobium, Mesorhizobium, Flavobacterium, Rhodococcus, and Serratia that have attracted the attention of agriculturists as soil inoculate to improve plant growth and yield (Anand et al., 2016; Sharma et al., 2013; Oteino et al., 2015)

\subsubsection{Potassium Solubilization}

Potassium is the third major essential macronutrient used for plant growth and concentrations of soluble potassium in the soil are very low because of more than $90 \%$ of potassium in the soil exists in the form of insoluble rock and silicate minerals. Without adequate potassium, the plants will have poorly developed roots, slowly growth, produce small seeds and have lower yield .Plant growth promoting rhizobacteria are able to solubilize potassium rock through production and secretion of organic acids that have the potential to solubilize potassium. The most known Potassium solubilizing rhizobacteria are Acidothiobacillus ferrooxidans, Bacillus edaphicus, Bacillus mucilaginosus, Burkholderia, Paenibacillus sp. and Pseudomonas has been reported to release potassium in accessible form from potassium bearing minerals in soils Thus, application of potassium solubilizing plant growth promoting rhizobacteria as biofertilizer in agriculture improvement can reduce the use of agrochemicals and support eco-friendly crop production(Liu et al., 2012; Kumar and Dubey, 2012; Han and Lee, 2006; Parmar and Sindhu , 2013).

\subsubsection{Siderophore Production}

Siderophores are used for plants in both direct and indirect enhancement mechanism of plant growth by plant growth promoting rhizobacteria. Iron is an essential micronutrient for all organisms that can live in the biosphere based on the fact that iron is the fourth most abundant element on earth but in aerobic soil iron is not readily assimilate by either bacteria or plants because ferric ion or Fe+3(which is the predominant form in nature) is only sparingly soluble so that the amount of iron available for assimilation by living organisms is extremely low. Microorganisms have evolved specialized 
mechanisms for the assimilation of iron by producing low molecular weight iron-chelating compounds known as siderophore, which transport this element into their cells. Depending on the characteristic functional group Siderophores are divided into three main families those are hydroxamates, catecholates and carboxylates. Currently more than 500 different types of siderophore are available but not fully characterized and large number of plant growth promoting rhizobacteria including Aeromonas, Azadirachta, Azotobacter, Bacillus, Burkholderia, Pseudomonas, Rhizobium, Serratia and Streptomyces sp (Majf, 2005; Sujatha and Ammani, 2013; Schwyn and Neilands,1987; Cornelis, 2010; Arora et al., 2013).

\subsubsection{Phytohormone Production}

A wide range of microorganisms found in the rhizosphere are able to produce Phytohormone substances that can regulate plant growth and development. Plant growth promoting rhizobacteria produce Phytohormone such as auxins, cytokinins, gibberellins, Ethylene and Indole Acetic Acid (IAA) can affect cell proliferation in the root architecture by overproduction of lateral roots and root hairs with a subsequent increase of nutrient and water uptake ( Miransari and Smith, 2014; Glick et al., 2007; Kang et al., 2010; Spaepen and Vanderleyden, 2011).

\subsubsection{Exopolysaccharide Production (Epss)}

Exopolysaccharides (EPSs) is a high molecular weight, biodegradable polymer that are produced biologically from monosaccharide residues and their derivatives by diverse type of bacteria, algae, and plants. EPSs play a central role for traits that are directly responsible for plant growth and crop production thus are maintaining water potential, aggregating soil particles, ensuring obligate contact between plant roots and rhizobacteria, sustaining plants under stress conditions (saline soil, dry weather, or water logging) or pathogenesis and the most EPS producing PGPR bacterial that have an important role increasing soil fertility and contributing to sustainable agriculture are Rhizobium leguminosarum, Azotobacter vinelandii, Bacillus drentensis, Enterobacter cloacae, Agrobacterium sp., Xanthomonas sp., and Rhizobium(Sanlibaba and Cakmak, 2016; Pawar et al., 2016; Mahmood et al., 2016).

\subsubsection{Production of Protective Enzymes}

Enzyme production is the indirect mechanism that use PGPR bacteria to promote plant growth by producing effective enzyme that control phytopathogenic agents that attack plant, the most enzyme that PGPR bacteria produce and capable of lysing cell walls and neutralizing pathogens are $\beta-1,3-$ glucanase, ACC-deaminase, and chitinase and Most of the fungal plant pathogen cell wall components are $\beta-1,4-\mathrm{N}$-acetyl-glucoseamine and chitin so bacteria such as Pseudomonas fluorescens LPK2 and Sinorhizobium fredii KCC5 can produce the enzyme $\beta$-1,3-glucanase- and chitinase to control fungal growth and promote plant growth(Meena et al., 2016; Goswami et al., 2016; Ramadan et al, 2016).

\subsubsection{Disease Resistance Antibiosis}

Disease resistance antibiosis is Utilization of microbial antagonists against plant pathogens by producing antibiotic and control pathogen for agricultural crops and currently they can be substitute chemical pesticides. PGPR, like Bacillus spp. and Pseudomonas sp., play a major role inhibiting pathogenic microorganisms by producing antibiotics. The production of antibiotics by PGPR against several plant pathogens has become one of the most effective and most studied bio-control mechanism (Ulloa et al., 2015).

\subsubsection{Induced Systemic Resistance (ISR)}

Induced resistance are defined as a plant physiological state that enhance defensive capacity in response to specific environmental stimuli most of for biotic challenges. Biopriming plants with some plant growth promoting rhizobacteria can also provide systemic resistance against a broad spectrum of plant pathogens such as fungal diseases, bacterial diseases and viral diseases, in some instances even damage caused by insects and nematodes can be reduced after application of plant growth promoting rhizobacteria.ISR involves jasmonate and ethylene signaling within the plant and these hormones stimulate the host plant defense responses against a variety of plant pathogens. Example of potential PGPR bacteria are lipopolysaccharides (LPS), flagella, siderophores, cyclic lipopeptides, 2,4diacetylphloroglucinol, homoserine lactones, and volatiles like, acetoin and 2, 3-butanediol (Glick, 2012; Doornbos et al ., 2012; Naznin et al., 2012; Avis et al., 2008). 


\subsubsection{Stress Management}

Stress is any kind of factor that have a negative effect on plant growth and development in different condition and increases the formation of reactive oxygen species (ROS) like ( $\mathrm{H} 2 \mathrm{O} 2, \mathrm{O}_{2}-$, and $\mathrm{OH}-$ ), ROS production causes oxidative stress that damages plants by oxidizing photosynthetic pigments, membrane lipids, proteins, and nucleic acids. Plants are frequently subjected to various environmental stresses such as both biotic and abiotic type stress and plants have the nature to developed specific response mechanisms for type of stress and PGPR bacteria help the plant to give the response to stress (Ramegowda and Senthil, 2015; Foyer et al., 2016)

\section{Abiotic Stress Tolerance}

Abiotic stress defined as non living thing that can happen suddenly without the intervention of mankind that cannot control at a time the best example are high wind, extreme temperature, drought, salinity, floods....... etc have a high negative impact on survival, biomass production, and production of staple food crops and have harm on food security worldwide. From the other abiotic stress occurs by drought, salinity, and high temperature is the most dominant abiotic stress limiting both plant growth and productivity so that PGPR bacteria have their contribution for remove the effect of abiotic stress on plant, The use of PGPR effect in plant abiotic stress management are by means of neutralize the toxic effect and improved leaf water status, particularly under salinity and other abiotic stress conditions through bacterial strains such as Pseudomonas putida and Pseudomonas fluorescens (Vejan et al., 2016; Baharlouei et al., 2011; Naveed et al., 2014).

\section{Biotic Stress Tolerance}

Biotic stress is defined as one type of stress that are caused by different kind of living pathogens such as bacteria, viruses, fungi, nematodes, protists, insects, and viroids those have a results in a significant reduction in agricultural yield and also biotic stress has adverse impacts on plant on their coevolution, population dynamics, ecosystem nutrient cycling, natural habitat ecology, and horticultural plant health but those problems can be solved know a day by using PGPR bacteria like Paenibacillus polymyxa strains, Bacillus amyloliquefaciens strain, B. licheniformis strain, B. thuringiensis strain,P. favisporus strain, and B. subtilis strain (Haggag et al., 2015; Gusain et al.,2015; Ngumbi and Kloepper, 2016).

\subsection{Biotechnology to Access the Function of Unknown Soil Microbes}

The earth biosphere is dominated by microorganisms that have various function and contains about 4 $6 \times 1030$ prokaryotic cells Thus, microorganisms are highly diverse group of organisms and constitute about $60 \%$ of the Earth's biomass (Singh et al, 2009).

Microorganisms have the key function in ecological processes such as soil structure formation, promoting plant growth, decomposition of organic matter and xenobiotic, and recycling of essential elements as I mention in the above such as carbon, nitrogen, phosphorous, and sulfur and nutrients. Thus microbes play a critical role in modulating global biogeochemical cycles and influence all lives on Earth and all organisms in the biosphere either directly or indirectly depend on microbial activities However, due to their general unculturability it is believed that only a small percentage of bacteria in nature can be cultured and in the present era of biotechnology new culture independent technology for the study of microbes inhabiting different environments are developed which are called Metagenomic is the culture independent analysis of a mixture of microbial genomes (Schloss et al., 2003; Riesenfeld et al 2004; Tringe and Rubin, 2005; Garbeva et al., 2004)

Metagenomic is defined as the application of modern genomics techniques to the study of communities of microbial organisms directly in their natural environments, bypassing the need for isolation and laboratory cultivation of individual species or the sequencing and analysis of genomic data taken directly from the environment and a new and rapidly developing field that makes it possible to study uncultured organisms by means of isolation of bacterial DNA directly from environmental samples has become a useful tool in molecular biology and biotechnology. Metagenomic can answering questions commonly asked in microbiology such as 'Which species inhabit a given environment?' and 'What are these microbes doing and how are they doing it?' by taking environmental habitat bacterial DNA or RNA sequencing using next-generation sequencers for sequence assembly, gene prediction, functional and metabolic analysis, taxonomic binning and comparative analysis of the sequence data using specialized bioinformatics methods and tools (Chen \&Pachter, 2005; Beja et al., 2000; Agnieszka et al, 2015; Kunin et al., 2008; Wooley et al., 2010) 


\subsubsection{Metagenomic Approach}

Metagenomic have three different approach that are used to understand the composition of environmental microbes those are

Functional Analysis Approach: which is involves the expression of genes from the environment in different hosts, such as E. coli. Once genes are expressed the hosts are screened for discovering functionality of interest. This approach yielded several important findings, including the discovery of antibiotic resistant genes from environmental organisms (Riesenfeld et al., 2004).

Sequence Based Approach: which are involved in sequences that contain interesting genes, such as 16S rDNA are cloned and identify bacterial type (Beja et al., 2000)

Environment Based Approach: which are involved take the entire DNA present in the environment is screened and analyzed. This approach provides a global view of an entire population rather than the species-specific view of the other two approaches. In this approach the DNA is sequenced using the Whole Genome Shotgun (WGS) sequencing technique in which the DNA is broken to small pieces that can be sequenced. WGS was first used for the sequencing of single genomes (Myers et al., 2000; Venter et al., 2001)

\subsubsection{Metagenomic Procedure}

Metagenomic work has several procedures for effective underfunding of the function and diversity of environmental biome the most important metagenomics process which relies on the efficiency of three main steps such as:-Sampling and nucleic acids extraction, Library construction and Analysis of Metagenomic libraries (Shakira, 2010).

Sampling and Nucleic Acids Extraction: For metagenomics research process the samples could be taken from any environment such as soil or habitat including the GI ecosystem, Specifically, soil microbial communities are composed of a mixture of archaea, bacteria and protists displaying a diversity of cell wall characteristics and varying in their susceptibility to lysis . Environmental Sample processing is the first and most crucial step in Metagenomic study because of the DNA that are extracted from the sample should be representative of all cells present in the sample and sufficient amounts of high-quality nucleic acids must be obtained for subsequent library production and sequencing (Kauffmann et al., 2004; Ghazanfar \& Azim, 2009; Delmont et al., 2011)

There are special techniques are required for their quality DNA extraction Although have various kits are commercially available for DNA isolation from any environmental samples specifically the soil microbial community have two types of extraction techniques such as 1.direct, in situ, extraction where the cells are lysed in the soil sample and then the DNA is extract. 2. Indirect extraction techniques, where the cells are removed from the soil and then lysed for DNA recovery but soil have complex matrix which containing many substances that can be degreed our extracted DNA and make low quality for further Metagenomic research. the most known substance are humic acids, which can be co-extracted during DNA isolation and degreed our DNA so it need remove from our sample DNA by different method such as Sephadex G-200 spin columns and pulse field electrophoresis are developed to remove the problem (Schmeisser et al., 2007; Quaiser et al.,2002)

Construction of a Metagenomic Library: After sampling DNA isolation and purification is followed by the construction of DNA libraries in suitable cloning methods such as modern PCR method and conventional method such as vectors and host strains. The classical approach includes the construction of small insert libraries $(<10 \mathrm{~kb})$ in a standard sequencing vector and in Escherichia coli as a host strain (Beja et al., 2000; Rondon et al., 2000)

Analysis of Metagenomic Libraries: These steps are the most and crucial to finalize metagenomics research work for any environmental sample and use two methods for the analysis of genetic material and interpretation of Metagenomic library those are

Sequence-Based Metagenomics: Sequence-based metagenomics provides information on the distribution of functions in a community, linkage of traits, genomic organization and horizontal gene transfer. Approaches typically involve either sequencing of random clones to accumulate vast stores of sequence information or identification of clones based on methods that detect a particular sequence. heterologous expression, in which clones that express the desired function are identified. An important limitation to heterologous expression is that the domesticated host bacterium must be able to express (transcribe and translate) the genes for the products to be detected; (ii) selections, in which the clone expressing the desired function grows and others do not. Selections provide the most 
powerful approach to finding rare clones. Examples of selectable characteristics include antibiotic resistance and metal resistance. 'functional-anchor approach' involves identifying all of the clones that express a certain function and sequencing them completely to determine the diversity of genomic environments from which that function originates and have to study what are the function os that specific microbes for a given plant so biotechnology too have a crucial role in this area to identify the microbes that associated with plant and what are the function of those associated microbes for plant are understand by functional analysis of metagenomics (Shakira et al., 2010).

\section{CONCLUSION}

To sustaining living organism specially mankind on the earth Agriculture and soil have been carrying the burden but exploitation of resources has limited the productive so humans are looking for alternative sources to fulfill of their livelihood needs through the help of biotechnology for their needs. PGPR plays an important role to fulfill of mankind livelihood needs by means of improving crop productivity through enhancing plant growth, remediating and managing contaminated and degraded and controlling pesticide pollution, nitrogen, and phosphorous runoff. However, chemical fertilizers and pesticides are not only hazardous for human consumption but can also disturb the ecological balance. Moreover, they have entered the food chain through different sources. Such changes can alter plant-microbe interactions by modifying microbial biology and biogeochemical cycles. Application of modern tools and techniques biotechnology for enhancement of PGPR can serve as key in sustainable agriculture by improving soil fertility, plant tolerance, crop productivity, and maintaining a balanced nutrient cycling. Further studies on selecting suitable rhizosphere microbes and producing microbial communities along with exploring multidisciplinary research that combines applications in biotechnology, nanotechnology, agro biotechnology, chemical engineering and material science and bringing together different ecological and functional biological approaches can provide new formulations and opportunities with immense potential for Ethiopia.

\section{REFERENCES}

[1] Ahemad, M. and Kibret, M., 2014. Mechanisms and applications of plant growth promoting rhizobacteria: current perspective. Journal of King Saud University-Science, 26(1), pp.1-20.

[2] Ahemad, M., 2012, Implications of bacterial resistance against heavy metals in bioremediation: a review. IIOABJ 3, 39-46.

[3] Ahemad, M., Kibret, M., 2014. Mechanisms and applications of plant growth promoting rhizobacteria: current perspective. J. King Saud Univ. Sci. 26, 1-20.

[4] Ahmad, F.; Ahmad, I.; Khan, M.S., 2008. Screening of free-living rhizospheric bacteria for their multiple plant growth promoting activities. Microbiol. Res, 163, 173-181.

[5] Akhgar, R., Arzanlou, M., Bakker, P.A.H.M., Hamidpour, M., 2014. Characterization of 1aminocyclopropane-1-carboxylate (ACC) deaminase-containing Pseudomonas sp. In the rhizosphere of salt-stressed canola. Pedosphere 24, 161-468.

[6] Area, J.M., Pozo, M.J., Azcon, R., Aguilar, C.A., 2005. Microbial co-operation in the rhizosphere. J. Exp. Bot. 56, 1761-1778.

[7] Arora NK, Tewari S, Singh R., 2013. Multifaceted Plant-Associated Microbes and Their Mechanisms Diminish the Concept of Direct and Indirect PGPRs. In: Arora NK (ed.) Plant Microbe Symbiosis: Fundamentals and Advances.Springer, 411-449

[8] Avis TJ, Gravel V, Antoun H, Tweddell RJ., 2008. Multifaceted beneficial effects of rhizosphere microorganisms on plant health and productivity. Soil Biol Biochem 40: 1733-1740.

[9] B. R. Glick, C. L. Patten, G. Holguin, and D. M. Penrose., 1999. Biochemical and Genetic Mechanisms Used by Plant Growth Promoting Bacteria, Imperial College Press, London, UK.

[10] B. R. Glick, Z. Cheng, J. Czarny, and J. Duan., 2007. "Promotion of plant growth by ACC deaminaseproducing soil bacteria," European Journal of Plant Pathology, vol. 119, no. 3, pp. 329-339.

[11] Baharlouei, J., Pazira, E., Khavazi, K., Solhi, M., 2011. Evaluation of inoculation of plant growthpromoting rhizobacteria on cadmium uptake by canola and barley. 2nd Int. Conf. Env. Sci. Tech. 2, 28-32.

[12] Beja, O., L. Aravind, et al. 2000. "Bacterial rhodopsin: evidence for a new type of phototrophy in the sea." Science 289(5486): 1902-1906.

[13] Bhardwaj, D., Ansari, M.W., Sahoo, R.K., Tuteja, N., 2014. Biofertilizer function as key player in sustainable agriculture by improving soil fertility, plant tolerance and crop productivity. Microbial. Cell Fact. 13 (66), 1-10.

[14] Bhattacharyya, P.N., Jha, D.K., 2012. Plant growth-promoting rhizobacteria (PGPR): emergence in agriculture. World J. Microbial. Biotechnol. 28, 1327-1350. 
[15] Caraglia, M., Rosa, G.D., Abbruzzese, A., Leonetti, C., 2011. Nanotechnologies: new opportunities for old drugs. the case of amino-bisphosphonates. Nanomedic.Biotherapeu Dis. 1, 103e.

[16] Chandler, D., Davidson, G., Grant, W.P., Greaves, J., Tatchell, G.M., 2008. Microbial biopesticides for integrated crop management: an assessment of environmental and regulatory sustainability. Trends Food Sci. Tech. 19, 275-283.

[17] Chen K., \& Pachter L., 2005. Bioinformatics for whole-genome shotgun sequencing of microbial communities. PLoS Comp Biol1 (2), pp. e24.

[18] Cornelis P., 2010. Iron uptake and metabolism in pseudomonads. Appl Microbiol Biotechnol 86: 1637 1645.

[19] Damam, M., Kaloori, K., Gaddam, B., Kausar, R., 2016. Plant growth promoting substances (phytohormones) produced by rhizobacterial strains isolated from the rhizosphere of medicinal plants. Int. J. Pharm. Sci. Rev. 37 (1), 130-136.

[20] Delmont TO, Robe P, Clark I, Simonet P, Vogel TM.2011. Metagenomic comparison of direct and indirect soil DNA extraction approaches. J Microbiol Methods 2011, 86:397-400.

[21] Dixshit, A., Shukla, S.K., Mishra, R.K., 2013. Exploring Nanomaterials with PGPR in Current Agriculture Scenario PGPR with Special Reference to Nanomaterials. Lab Lambert Acedamic Publication, Germany $51 \mathrm{pp}$.

[22] Doornbos RF, van Loon LC, Peter AHM, Bakker A., 2012. Impact of root exudates and plant defense signaling on bacterial communities in the rhizosphere. Rev Sustain Dev 32: 227-243.

[23] Felczykowska, A., Krajewska, A., Zielińska, S. and Łoś, J.M., 2015. Sampling, metadata and DNA extraction-important steps in metagenomic studies. Acta Biochimica Polonica, 62(1).

[24] Foyer, C.H., Rasool, B., Davey, J.W., Hancock, R.D., 2016. Cross-tolerance to biotic and abiotic stresses in plants: a focus on resistance to aphid infestation. J. Exp. Bot. 7,2025-2037.

[25] Gaby JC, Buckley DH., 2012. A comprehensive evaluation of PCR primers to amplify the nifH gene of nitrogenase. PLoS One 7: e42149.

[26] Galloway, J.N.; Townsend, A.R.; Erisman, J.W.; Bekunda, M.; Cai, Z.; Freney, J.R.; Martinelli, L.A.; Seitzinger, S.P.; Sutton, M.A., 2008. Transformation of the nitrogen cycle: Recent trends, questions, and potential solutions Science, 320, 889-892.

[27] Garbeva, P., van Veen, J.A., van Elsas, J.D. 2004. Microbial diversity in soil: selection microbial populations by plant and soil type and implications for disease suppressiveness. Annu. Rev.Phytopathol. 42:243-270.

[28] Garcia, F.P., Menendez, E., Rivas, R., 2015. Role of bacterial bio fertilizers in agriculture and forestry. AIMS Bioeng. 2, 183-205.

[29] Ghazanfar S. \& Azim A., 2009. Metagenomics and its Application in Rumen Ecosystem:Potential Biotechnological Prospects.Pakistan Journal of Nutrition 8 (8), pp.1309-1315.

[30] Ghazanfar, S., Azim, A., Ghazanfar, M.A., Anjum, M.I. and Begum, I., 2010. Metagenomics and its application in soil microbial community studies: biotechnological prospects. Journal of Animal \& Plant Sciences, 6(2), pp.611-622.

[31] Glick BR, Todorovic B, Czarny J, Cheng Z, Duan J, et al. ., 2007. Promotion of plant growth by bacterial ACC deaminase. Crit Rev Plant Sci 26: 227-242.

[32] Glick BR., 2012. Plant growth-promoting bacteria: mechanisms and applications. Scientifica (Cairo) 2012: 963401.

[33] Glick, B.R., 2012. Plant Growth-Promoting Bacteria: Mechanisms and Applications. Hindawi Publishing Corporation, Scientifica.

[34] Glick, B.R., 2012. Plant growth-promoting bacteria: mechanisms and applications. Scientifica, 2012.

[35] Goswami, D., Pithwa, S., Dhandhukia, P., Thakker, J.N., 2014. Delineating Kocuria turfanensis 2M4 as a credible PGPR: A novel IAA producing bacteria isolated from saline desert. J. Plant Interact. 9, 566-576.

[36] Goswami, D., Thakker, J.N., Dhandhukia, P.C., 2016. Portraying mechanics of plant growth promoting rhizobacteria (PGPR): a review. Cogent Food Agric. 2, 1-19.

[37] Gouda, S., Kerry, R.G., Das, G., Paramithiotis, S., Shin, H.S. and Patra, J.K., 2017. Revitalization of plant growth promoting rhizobacteria for sustainable development in agriculture. Microbiological research.

[38] Gray, E.J.; Smith, D.L., 2005. Intracellular and extracellular PGPR: Commonalities and distinctions in the plant-bacterium signaling processes. Soil Biol. Biochem., 37, 395-412.

[39] Gupta G, Parihar SS, Ahirwar NK, Snehi SK, Singh V., 2015. Plant Growth Promoting Rhizobacteria (PGPR): Current and Future Prospects for Development of Sustainable Agriculture. J Microb Biochem Technol 7: 096-102.doi:10.4172/1948-5948.1000188 
[40] Gupta, G., Parihar, S.S., Ahirwar, N.K., Snehi, S.K., Singh, V., 2015. Plant growth promoting Rhizobacteria (PGPR): Current and future prospects for development of sustainable agriculture. J. Microbiol. Biochem. 7, 96-102.

[41] Gupta, G., Parihar, S.S., Ahirwar, N.K., Snehi, S.K., Singh, V., 2015. Plant growth promoting Rhizobacteria (PGPR): Current and future prospects for development of sustainable agriculture. J. Microbiol. Biochem. 7, 96-102.

[42] Gupta, G., Parihar, S.S., Ahirwar, N.K., Snehi, S.K., Singh, V., 2015. Plant growth promoting Rhizobacteria (PGPR): Current and future prospects for development of sustainable agriculture. J. Microbiol. Biochem. 7, 96-102.

[43] Gupta, S., Meena, M.K., Datta, S., 2014. Isolation, characterization of plant growth promoting bacteria from the plant Chlorophytum borivilianum and in-vitro screening for activity of nitrogen fixation, phosphate solubilization and IAA production. Int. J.Curr. Microbial. Appl. Sci. 3, 1082-1090.

[44] Gusain, Y.S., Singh, U.S., Sharma, A.K., 2015. Bacterial mediated amelioration of drought stress in drought tolerant and susceptible cultivars of rice (Oryza sativa L.). Afr. J.Biotechnol. 14, 764-773.

[45] Haggag, W.M., Abouziena, H.F., Abd-El-Kreem, F., Habbasha, S., 2015. Agriculture biotechnology for management of multiple biotic and abiotic environmental stress in crops. J. Chem. Pharm. 7 (10), 882889.

[46] Han HS, Lee KD., 2006. Effect of co-inoculation with phosphate and potassium solubilizing bacteria on mineral uptake and growth of pepper and cucumber. Plant Soil Environ 52: 130-136.

[47] Hayat, R., Ali, S., Amara, U., Khalid, R. and Ahmed, I., 2010. Soil beneficial bacteria and their role in plant growth promotion: a review. Annals of Microbiology, 60(4), pp.579-598.

[48] Hayat, R., Ali, S., Amara, U., Khalid, R., Ahmed, I., 2010. Soil beneficial bacteria and their role in plant growth promotion: a review. Ann Microbiol. 60, 579-598.

[49] E. G. Salamone, R. K. Hynes, and L. M. Nelson., 2005. "Role of cytokinins in plant growth promotion by rhizosphere bacteria, in PGPR: Biocontrol and Biofertilization, Z. A. Siddiqui, Ed., pp.173-195, Springer, Amsterdam, Netherlands.

[50] J. M. Lynch, Ed., 1990. the Rhizosphere, Wiley-Interscience, Chichester,UK.

[51] Kang BG, Kim WT, Yun HS, Chang SC., 2010. Use of plant growth-promoting rhizobacteria to control stress responses of plant roots. Plant Biotechnol Rep 4: 179-183.

[52] Kang, B.G., Kim, W.T., Yun, H.S., Chang, S.C., 2010. Use of plant growth-promoting rhizobacteria to control stress responses of plant roots. Plant Biotechnol. Rep. 4,179-183.

[53] Kauffmann I.M., Schmitt J. \& Schmid R.D., 2004.DNA isolation from soil samples for cloning in different hosts. Appl Microbiol Biotechnol, 64: 665-670.

[54] Khan, M.S., Zaidi, A., Wani, P.A., Oves, M., 2009. Role of plant growth promoting rhizobacteria in the remediation of metal contaminated soils. Environ. Chem. Lett. 7, 1-19.

[55] Kumar P, Dubey RC., 2012. Plant Growth Promoting Rhizobacteria for Biocontrol of Phytopathogens and Yield Enhancement of Phaseolus vulgaris. J Curr Pers Appl Microbiol 1: 6-38.

[56] Kumar, A., 2016. Phosphate solubilizing bacteria in agriculture biotechnology: diversity, mechanism and their role in plant growth and crop yield. Int. J. Adv. Res. 4 (4), 116-124.

[57] Kundan, R., Pant, G., Jado, N., Agrawal, P.K., 2015. Plant growth promoting rhizobacteria: mechanism and current prospective. J. Fertilizers Pesticides 6, 2.

[58] Kunin V, Copeland A, Lapidus A. 2008.A bioinformatician's guide to metagenomics. Microbiol Mol Biol Rev;72:557-78.

[59] L. Schoenborn, P. S. Yates, B. E. Grinton, P. Hugenholtz, and P.H. Janssen., 2004. "Liquid serial dilution is inferior to solid media for isolation of cultures representative of the phylum-level diversity of soil bacteria," Applied and Environmental Microbiology, vol. 70, no. 7, pp. 4363-4366.

[60] Liu D, Lian B, Dong H., 2012. Isolation of Paenibacillus sp. and assessment of its potential for enhancing mineral weathering. Geomicrobiology J 29: 413-421.

[61] M. Lucy, E. Reed, and B. R. Glick, 2004 "Applications of free living plant growth-promoting rhizobacteria," Antonie van Leeuwenhoek,vol. 86, no. 1, pp. 1-25.

[62] Ma JF ., 2005. Plant root responses to three abundant soil minerals: silicon, aluminum and iron. Crit Rev Plant Science 24: 267-281

[63] Mahmood, S., Daur, I., Al-Solaimani, S.G., Ahmad, S., Madkour, M.H., Yasir, M., Hirt, H.,Ali, S., Ali, Z., 2016. Plant growth promoting rhizobacteria and silicon synergistically enhance salinity tolerance of mung bean. Front. Plant Sci. 7, 1-14. 
[64] Meena, M.K., Gupta, S., Datta, S., 2016. Antifungal Potential of PGPR, their growth promoting activity on seed germination and seedling growth of winter wheat and genetic variability among bacterial isolates. Int. J. Curr. Microbial. Appl. Sci. 5 (1),235-243.

[65] Meyer, F., D. Paarmann, et al. 2008. "The metagenomics RAST server - a public resource for the automatic phylogenetic and functional analysis of metagenomes." BMC Bioinformatics 9: 386.

[66] Miransari M, Smith DL., 2014. Plant hormones and seed germination. Environmental and Experimental Botany 99: 110- 121

[67] Mishra, V.K., Kumar, A., 2009. Impact of metal nanoparticles on the plant growth promoting rhizobacteria. Digest J. Nanomat. Biostruct. 4 (3), 587-592.

[68] Naveed, M., Hussain, M.B., Zahir, Z.A., Mitter, B., Sessitsch, A., 2014. Drought stress amelioration in wheat through inoculation with Burkholderia phytofirmans strain PsJN. Plant Growth Regul. 73, $121-131$.

[69] Naznin HA, Kimura M, Miyazawa M, Hyakumachi M., 2012. Analysis of volatile organic compounds emitted by plant growth promoting fungus phoma sp. GS8-3 for growth promotion effects on tobacco. Microbe Environ 28: 42-49.

[70] Ngumbi, E., Kloepper, J., 2016. Bacterial-mediated drought tolerance: current and future prospects. Appl. Soil Ecol. 105, 109-125.

[71] Nivya, R.M., 2015. A Study on plant growth promoting activity of the Endophytic bacteria isolated from the root nodules of Mimosa pudica Plant. Int. J. Innov. Res. Sci. Er. Technol. 4, 6959-6968.

[72] P. J. Davies, 2004.Plant Hormones: Biosynthesis, Signal Transduction, Action!, Kluwer Academic, Dordrecht, Netherlands.

[73] Paredes, S.H., Lebeis, S.L., 2016. Giving back to the community: microbial mechanisms of plant-soil interactions. Funct. Ecol. 30 (7), 1-10.

[74] Parmar P, Sindhu SS., 2013. Potassium Solubilization by Rhizosphere Bacteria: Influence of Nutritional and Environmental Conditions. J Microbiol Res 3: 25-31.

[75] Pawar, S.T., Bhosale, A.A., Gawade, T.B., Nale, T.R., 2016. Isolation, screening and optimization of exopolysaccharide producing bacterium from saline soil. J. Microbiol. Biotechnol. Res. 3 (3), 24-31.

[76] Quaiser A., Ochsenreiter T., Klenk H.P., Kletzin A.,Treusch A.H., Meurer, G., Eck J., SensenC.W. \& Schleper C., 2002. First insight into the genome of an uncultivated crenarchaeote from soil. Environ.Microboil. 4, pp. 603-611.

[77] Rajkumar, M., Ae, N., Prasad, M.N.V., Freitas, H., 2010. Potential of siderophore-producing bacteria for improving heavy metal phytoextraction. Trends Biotechnol. 28, 142-149.

[78] Ramadan, E.M., AbdelHafez, A.A., Hassan, E.A., Saber, F.M., 2016. Plant growth promoting rhizobacteria and their potential for biocontrol of phytopathogens. Afr. J. Microbiol. Res. 10, $486-504$.

[79] Ramegowda, V., Senthil-Kumarb, M., 2015. The interactive effects of simultaneous biotic and abiotic stresses on plants: mechanistic understanding from drought and pathogen combination. J. Plant Physiol. $176,47-54$.

[80] Reed, S.C., Cleveland, C.C., Townsend, A.R., 2011. Functional ecology of free-living nitrogen fixation: a contemporary perspective. Annu. Rev. Ecol. Environ. Syst. 42,489-512.

[81] Riesenfeld C.S., Goodman R.M. \& Handelsman J.,2004. Uncultured soil bacteria are a reservoir of new antibiotic resistance genes. Environ Microbiol 6, pp. 981 - 989.

[82] Riesenfeld, C. S., R. M. Goodman, et al. 2004. "Uncultured soil bacteria are a reservoir of new antibiotic resistance genes." Environ Microbiol 6(9): 981-989.

[83] Rondon M.R., August P.R., Bettermann A.D.,Brady S.F., Grossman T.H., Liles M.R.,Loiacono K.A., Lynch B.A., MacNeil I.A.,Minor C., Tiong C.L., Gilman M., OsburneM.S., Clardy J., Handelsman J. \& Goodman R.M., 2000. Cloning the soil Metagenomic: a strategy for accessing the genetic and functional diversity of uncultured microorganisms. Appl. Environ. Microbiol., 66, pp. 2541-2547.

[84] Sanlibaba, P., Cakmak, G.A., 2016. Exo-polysaccharides production by lactic acid bacteria. Appl. Microbiol. 2 (2), 1-5.

[85] Schloss P.D. \& Handelsman J., 2003.Biotechnological prospects from metagenomics. Curr. Opin. Biotechnol. 14,pp. 303-310.

[86] Schmeisser C., Helen S. \& Wolfgang R.S., 2007.Metagenomics, biotechnology with nonculturable microbes. Appl Microbiol Biotechnol 75, pp. 955-962

[87] Schwyn B, Neilands JB., 1987. Universal chemical assay for the detection and determination of siderophores. Anal Biochem 160: 47-56.

[88] Shridhar, B.S., 2012. Review: nitrogen fixing microorganisms. Int. J. Microbial. Res. 3 (1),46-52.

International Journal of Research Studies in Microbiology and Biotechnology (IJRSMB) $\quad$ Page | 26 
[89] Singh, B.K., Campbell, C.D., Sorenson, S.J., Zhou, J. 2009. Soil genomics. Nature Reviews Microbiology 7:756 doi:10.1038/nrmicro2119-c1.

[90] Singh, R.P., Jha, P.N., 2015. Molecular identification and characterization of rhizospheric bacteria for plant growth promoting ability. Int. J. Curr. Biotechnol. 3, 12-18.

[91] Spaepen S, Vanderleyden J., 2011. Auxin and plant-microbe interactions. Cold Spring Harb Perspect Biol 3: a001438.

[92] Subramanian, K.S., Tarafdar, J.C., 2011. Prospects of nanotechnology in Indian farming.Indian J. Agri. Sci. 81, 887-893.

[93] Sujatha N, Ammani K., 2013. Siderophore production by the isolates of fluorescent Pseudomonads. Int J Cur Res Rev 5: 1-7

[94] Tringe SG, Rubin EM. 2005. Metagenomics: DNA sequencing of environmental samples. Nat Rev Genet; 6:805-14.

[95] Ulloa-Ogaz, A.L., Munoz-Castellanos, L.N., Nevarez-Moorillon, G.V., 2015. Biocontrol of phytopathogens: Antibiotic production as mechanism of control, the battle against microbial pathogens. In: In: Mendez Vilas, A. (Ed.), Basic Science, Technological advance and educational programs 1. pp. 305309.

[96] Vacheron, J., Desbrosses, G., Bouffaud, M.L., Touraine, B., Moënne-Loccoz, Y., Muller, D.,Legendre, L., Wisniewski-Dyé, F., Combaret, C.P., 2013. Plant growth promoting rhizobacteria and root system functioning. Front. Plant Sci. 4 (356), 1-19.

[97] Vejan, P., Abdullah, R., Khadiran, T., Ismail, S. and Nasrulhaq Boyce, A., 2016. Role of plant growth promoting rhizobacteria in agricultural sustainability - a review. Molecules, 21(5), p.573.

[98] Vejan, P., Abdullah, R., Khadiran, T., Ismail, S., Boyce, A.N., 2016. Role of plant growth promoting Rhizobacteria in agricultural sustainability- a review. Molecules 21 (573),1-17.

[99] Venter, J. C., K. Remington, et al. 2004. "Environmental genome shotgun sequencing of the Sargasso Sea." Science 304(5667): 66-74.

[100]Viveros, O.M., Jorquera, M.A., Crowley, D.E., Gajardo, G., Mora, M.L., 2010. Mechanisms and practical considerations involved in plant growth promotion by rhizobacteria. J. Soil Sci. Plant Nutr. 10, $293-319$.

[101]Walker, T.S., Bais, H.P., Grotewold, E., Vivanco, J.M., 2003. Root exudation and rhizosphere biology. Plant Physiol. 132, 44-51.

[102]Wooley JC, Godzik A, Friedberg I. 2010. A primer on metagenomics. PLoSComput Biol;6:e1000667-79.

[103]World Population Clock: 7.6 Billion People., 2017. Worldometers". www.worldometers.info. Retrieved 2017-10-08.

[104]Xu, G., Fan, X., Miller, A.J., 2012. Plant Nitrogen assimilation and use efficiency. Ann.Rev. Plant Biol. 63, 153-182.

[105]Zaidi, A., Khan, M.S., Ahemad, M., Oves, M., 2009. Plant growth promotion by phosphate solubilizing bacteria. Acta Microbiol.Immunol. Hung. 56, 263-284.

[106]Zakry, F.A.A., Shamsuddin, Z.H., Khairuddin, A.R., Zakaria, Z.Z., Anuar, A.R., 2012. Inoculation of Bacillus sphaericus UPMB-10 to young oil palm and measurement of its uptake of fixed

Citation: Birhanu Babiye. "Plant Growth Promoting Bacteria and their Prospective Role for Crop Improvement", International Journal of Research Studies in Microbiology and Biotechnology (IJRSMB), vol. 5 , no. 1, pp. 16-27, 2019. Available: DOI: http://dx.doi.org/10.20431/2454-9428.0501003

Copyright: (C) 2019 Authors. This is an open-access article distributed under the terms of the Creative Commons Attribution License, which permits unrestricted use, distribution, and reproduction in any medium, provided the original author and source are credited. 